\title{
Isolation and genetic characterization of Lysinibacillus sphaericus strains found in mosquito larvae (Diptera: Culicidae)
}

This article was published in the following Dove Press journal:

Research and Reports in Tropical Medicine

I February 2017

Number of times this article has been viewed

\author{
Clara de Fátima Gomes \\ Cavados' \\ Eder Soares Pires' \\ Jeane Quintanilha Chaves' \\ Danielle Nunes Alvarez' \\ Helio Benites Gil² \\ Iris Braz Ribeiro de Oliveira ${ }^{2}$ \\ Andrea de Barros Pinto \\ Viviani Cunha ${ }^{2}$ \\ Carlos José Pereira da \\ Cunha de Araújo-Coutinho \\ 'Laboratory of Bacterial Physiology, \\ Fundação Oswaldo Cruz, Instituto \\ Oswaldo Cruz, Rio de Janeiro, \\ ${ }^{2}$ Superintendência de Controle de \\ Endemias - SUCEN, São Paulo, Brazil
}

Correspondence: Carlos José Pereira da Cunha de Araújo Coutinho Superintendência de Controle de Endemias - SUCEN, Cardeal Arcoverde, 2878, 05408-003 São Paulo, Brazil Email cjpcacoutinho@gmail.com
Introduction: Lysinibacillus sphaericus is a highly effective and specific bioinsecticide used for the control of Culicidae larvae.

Objective: This study aimed to identify and characterize L. sphaericus strains isolated from Culex quinquefasciatus larvae in Brazil.

Methods: C. quinquefasciatus larvae were collected from streams in the urban area of São Paulo state. L. sphaericus strains were identified through cytomorphology, biochemical, and physiological analyses. Qualitative bioassays were performed to evaluate the toxicity of the strains against $C$. quinquefasciatus. The crystal compound protein pattern of $L$. sphaericus strains was analyzed by sodium dodecyl sulfate polyacrylamide gel electrophoresis. Five reference strains were used as standards in all tests performed. Repetitive extragenic palindromic elements-polymerase chain reaction (REP-PCR) was utilized in an attempt to differentiate pathogenic and nonpathogenic isolates. Results: Twenty-one strains were isolated. Only one presented toxic activity against C. quinquefasciatus. REP-PCR results identified 23 patterns among the 26 strains used in the study, and the fragment analysis showed low similarity (16\%) between L. sphaericus isolates and the five reference strains.

Conclusion: Comparison of strains isolated in this study using REP-PCR showed a low similarity to other strains, demonstrating the high intraspecific variability for L. sphaericus.

Keywords: Lysinibacillus sphaericus, Culicidae, SDS-PAGE, qualitative bioassays, REP-PCR, mosquitoes, entomopathogenic bacteria

\section{Introduction}

Lysinibacillus sphaericus, previously described as Bacillus sphaericus, is an obligately aerobic, mesophilic, round-spore shaped bacterium that naturally occurs in soil. ${ }^{1}$ It is characterized by the lack of carbohydrate fermentation when evaluated using standard phenotypic tests for Bacillus identification. ${ }^{2}$ Some strains may be highly toxic to some species of mosquito larvae, such as Culex sp., Anopheles sp., and Psorophora sp., but show low toxicity against Aedes sp. larvae. ${ }^{3}$ However, strains of L. sphaericus can be found as part of the natural microbiota of these larvae without causing any disease. Moreover, the specificity of L. sphaericus for mosquito larvae eliminates the risks for nontarget organisms and vertebrates such as fish, birds, and mammals. ${ }^{3}$ For these reasons, this bacterium has been used for mosquito biocontrol. ${ }^{4}$

L. sphaericus is widely used for the control of Culex quinquefasciatus in the states of Pernambuco and São Paulo, Brazil, and for Anopheles spp. in the Amazon region. Other countries in Latin America, such as Colombia, Mexico, Guatemala, Nicaragua, and Honduras, have been subject to extensive tests of products based on 
L. sphaericus strain 2362 to control the vectors of malaria, obtaining promising results, with a $>90 \%$ reduction rate of anopheline populations. ${ }^{4}$

The mosquitocidal characteristics of L. sphaericus are attributed to the presence of two different types of toxins. The binary toxin (Bin) is expressed as a parasporal body divided into two polypeptides of 42 and $51 \mathrm{kDa}$, and is known as BinA and BinB, respectively. Both of these polypeptides are required for high toxicity to mosquito larvae. Some toxic strains also produce the 100,32 , and $35 \mathrm{kDa}$ toxins encoded, respectively, by $m t x 1, m t x 2$, and $m t x 3$ genes. Strains considered highly toxic are those that produce the binary toxin and also harbor $m t x$ genes. ${ }^{3}$ The mode of action of these crystal toxins is very similar to the Cry toxins of Bacillus thuringiensis serovar israelensis in mosquito larvae. ${ }^{5}$ The aim of this study was to identify and characterize several strains of $L$. sphaericus isolated from Culicidae larvae in Brazil.

\section{Methods}

\section{Collection of larvae and species identification}

Culex sp. and Aedes sp. larvae were collected from rivers in São Paulo state, Brazil, and transferred, on ice, to the laboratory where they were submitted to sterilization and heat treatment according to Alves ${ }^{6}$ and Cavados et al. ${ }^{7}$

Strains of L. sphaericus were identified using cytomorphology, biochemical, and physiological analyses, and the results were analyzed with the support of a dichotomous key. ${ }^{2}$

\section{Qualitative bioassays}

Qualitative bioassays were performed to evaluate the toxicity of isolated strains against C. quinquefasciatus Say (Diptera: Culicidae) larvae under laboratory conditions. As toxicity references, lineages of $L$. sphaericus nonmosquitocidal SSII-1 (LFB-FIOCRUZ 847) and L. sphaericus mosquitocidal 2362 (LFB-FIOCRUZ 736) were used. All lineages were tested in duplicate and larvae without bacterial suspensions were used as negative controls. The biological activity was evaluated according to Oliveira et $\mathrm{al}^{8}$ and Araújo da Silva et al. ${ }^{9}$

\section{Analyses of L. sphaericus crystal protein profile}

The protein profile of the crystal components of $L$. sphaericus strains was analyzed by sodium dodecyl sulfate polyacrylamide gel electrophoresis (SDS-PAGE), following the procedure described by Laemmli and Favre. ${ }^{10}$ Some modifications were made, such as growth in nutrient yeast extract salt media and use of Tris-EDTA (TE) buffer (Tris-HCl $1 \mathrm{M}$, pH 8.0; EDTA $0.5 \mathrm{M}, \mathrm{pH} 8.0$ ) in centrifugation. Electrophoresis was carried out on a $10 \%$ resolving gel $(\mathrm{pH} 8.0)$ and a $5 \%$ stacking gel (pH 6.8) at $90 \mathrm{~V}$ for 45 minutes.

The following were used as standards in all tests performed: 1) pathogenic L. sphaericus LFB-FIOCRUZ 736, serotype H5a5b, strain 2362; 2) pathogenic LFB-FIOCRUZ 735, serotype H5a5b, strain 1593; 3) nonpathogenic LFB-FIOCRUZ 847, serotype H2a2b, strain SS II-1; 4) nonpathogenic LFBFIOCRUZ 742, ATCC 14577 (homology group I); and 5) nonpathogenic LFB-FIOCRUZ 751, serotype H26a26b, strain 2315.

\section{Repetitive extragenic palindromic elements polymerase chain reaction (REP-PCR)}

In this study, REP-PCR was used in an attempt to differentiate pathogenic and nonpathogenic L. sphaericus isolates. DNA extraction was performed according to Nunes et al. ${ }^{11}$ The REP-PCR was performed as previously described by Reyes-Ramirez and Ibarra. ${ }^{12}$ The selection of primers was based on the genetic relationship between genus Bacillus and genus Lysinibacillus.

\section{Results}

Results of REP-PCR were transformed into binary matrices and evaluated by the NTSYSpc (Version 2.1) numerical analysis program. Profile analysis was performed based on the calculation of the Sørensen-Dice coefficient, used to establish the similarity matrix. This matrix was transformed into a dendrogram (Figure 1), using the unweighted pair group method according to Rohlf. ${ }^{13}$ A cophenetic matrix was constructed using the similarity matrix to test the validity of the generated clusters. Correlation (Mantel $t$-test) between the cophenetic and similarity matrices was determined using the MXCOMP module. ${ }^{14}$

Twenty-one strains were isolated during the study and identified by phenotypic features as L. sphaericus. In the qualitative bioassays, only the strain LFB-FIOCRUZ 1513 demonstrated toxicity against $C$. quinquefasciatus larvae. This result is in agreement with the protein profile obtained with SDS-PAGE, which showed that lineage LFB-FIOCRUZ 1513 shared the same protein pattern, with strain LFB-FIOCRUZ 736, flagellar serotype H5a5b, strain 2362 showing the two polypeptides of the binary toxin. Strain 2362 was used as active ingredient in L. sphaericus-based insecticides.

Based on the results obtained with REP-PCR, 23 different profiles were found among the 26 strains in the study. Pathogenic and nonpathogenic L. sphaericus strains could not be distinguished based on this criterion. Analysis of 


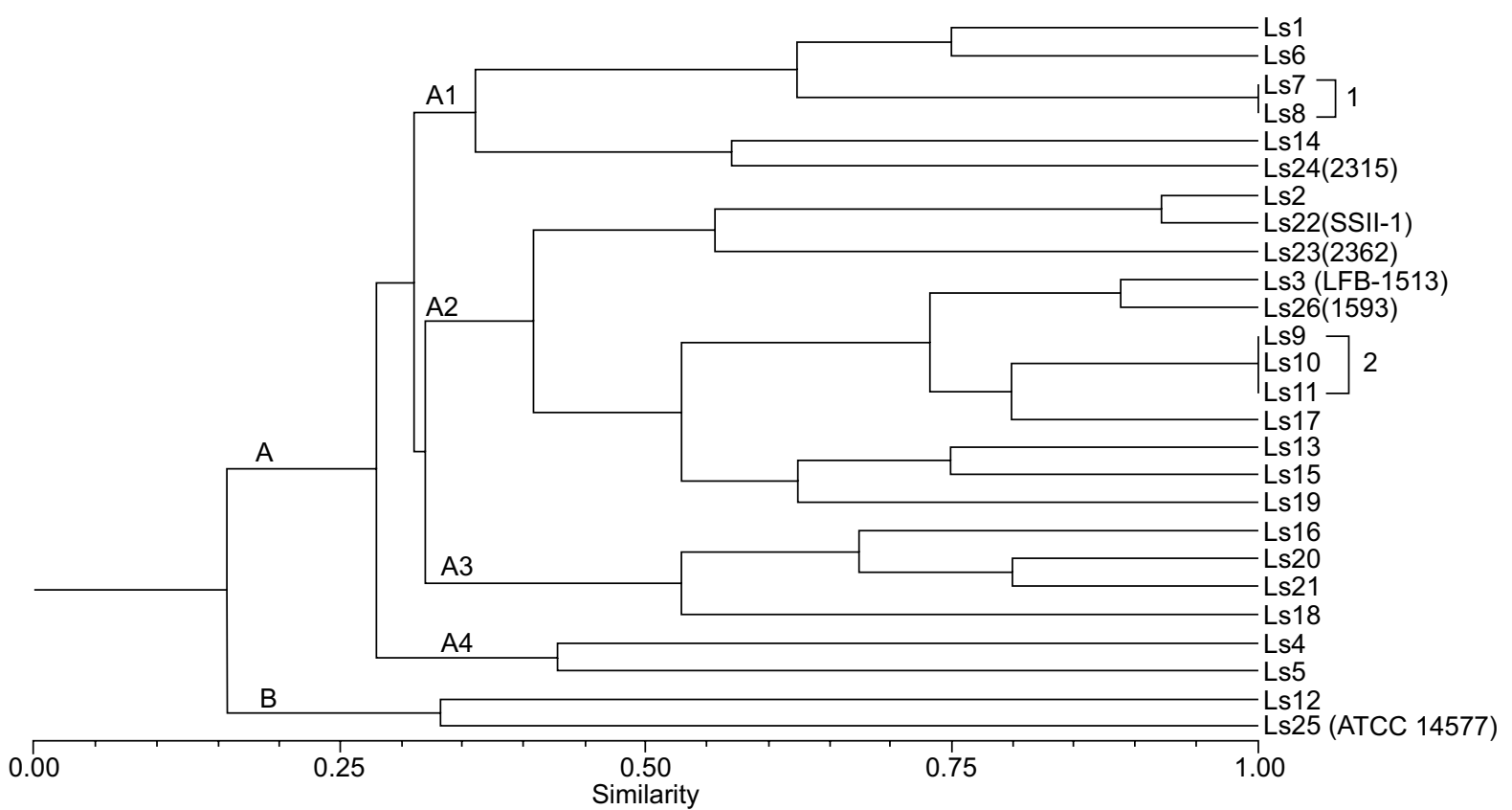

Figure I Dendrogram illustrating group A (with subgroups AI, A2, A3, and A4) and group B with increasing levels of similarity. Groups I and 2 comprise strains with $100 \%$ similarity.

Abbreviations: Ls, Lysinibacillus sphaericus; ATTC, American Type Culture Collection.

fragment profiles generated by REP-PCR demonstrated low genetic similarity (16\%) among the L. sphaericus isolates and the five reference strains. This result may be related to the high levels of genetic variability within this species. These strains were divided into two groups (A and B). Group A was split into subgroups (A1, A2, A3, and A4) with increasing levels of similarity between them; on the other hand, group B consisted of two L. sphaericus strains with only $34 \%$ similarity. PCR reactions were performed twice to validate the obtained data. The coefficient of cophenetic correlation in the dendrogram was relatively high (0.77), indicating the validity of the generated groups. ${ }^{14}$

\section{Discussion}

Miteva et $a{ }^{15}$ performed a comparative study of 15 strains, representing the five homologous groups of L. sphaericus, by applying two PCR methods: random amplified polymorphic DNA (RAPD) and REP-PCR fingerprinting. These molecular methods demonstrated highly variable patterns and allowed differentiation of the strains studied. Similarity matrix analysis revealed a low level of affinity among the different homology groups, and within groups I and III, which is evidence of the high genetic heterogeneity in L. sphaericus species.

Woodburn et $\mathrm{al}^{16}$ analyzed pathogenic and nonpathogenic strains of L. sphaericus with RAPD-PCR to determine their genetic relationships. These authors demonstrated, by the Jaccard coefficient, that pathogenic strains belonging to
DNA homology group IIA were similar to strains belonging to nonpathogenic homology groups, with an average level of similarity of $6.3 \%$. This technique has been used to differentiate several related species as well as strains of $L$. sphaericus. These results obtained using RAPD fingerprinting indicated that there is heterogeneity within L. sphaericus.

Among L. sphaericus strains, RAPD and REP-PCR revealed considerable genetic heterogeneity, which was confirmed by phylogenetic studies. The differences in pathogenicity can also assist taxonomic studies of the Lysinibacillus genus. ${ }^{15,17}$

Araújo da Silva et $\mathrm{al}^{9}$ performed REP-PCR and BOXPCR with 30 pathogenic strains of $L$. sphaericus to evaluate genetic diversity among strains isolated from different sources and localities in Brazil. DNA fingerprinting revealed five groups of similar strains by BOX-PCR and eight groups by REP-PCR. The cluster analysis indicated a high degree of diversity among the studied strains.

This paper is only a preliminary study of Bacillus species and species in associated genera isolated from healthy and diseased Culicidae larvae. Further isolation of new strains and use of molecular techniques will help in the characterization and population analysis of new bacterial strains. The use of REP-PCR with this pair of primers was apparently unsuccessful in distinguishing pathogenic and nonpathogenic L. sphaericus strains. This is due to the high intraspecific genetic variability for these regions amplified by the set of primers which appear to be unrelated to pathogenicity. It is worthwhile to note that this study was the first to use a pair of 
primers specific to the genus Bacillus to analyze the closely related genus Lysinibacillus. A literature search did not find any other article describing the utilization of this pair of primers or, even specific primers for Bacillus and related genera.

\section{Conclusion}

The present study is in agreement with data reported by other authors, where the genetic variability in the L. sphaericus population was analyzed and showed low similarity between the strains.

\section{Acknowledgment}

This study was financed by FAPESP (Proj. 2012/23947-0), the official agency for support of scientific research in São Paulo, Brazil

\section{Disclosure}

The authors report no conflicts of interest in this work.

\section{References}

1. Ahmed I, Yokota A, Yamazoe, A, Fujiwara, T. Proposal of Lysinibacillus boronitolerans gen. nov. sp. nov., and transfer of Bacillus fusiformis to Lysinibacillus fusiformis comb. nov. and Bacillus sphaericus to Lysinibacillus sphaericus comb. nov. Int J Syst Evol Microbiol. 2007;57(Pt 5): $1117-1125$.

2. Logan NA, Berge O, Bishop AH, et al. Proposed minimal standards for describing new taxa of aerobic, endospore-forming bacteria. Int $J$ Syst Evol Microbiol. 2009;59(Pt 8):2114-2121.

3. Lacey LA. Bacillus thuringiensis serovariety israelensis and Bacillus sphaericus for mosquito control. J Am Mosq Control Assoc. 2007; 23(Suppl 2):133-163.

4. Rabinovitch L, Araújo-Coutinho CJPC, Silva CMB, Alves RSA, Alves LFA, Cavados CFG. Bioprodutos à base de Bacillus entomopatogênicos em programas de controle de vetores na América Latina. In: Alves SB, Lopes RB, editors. Controle microbiano de pragas na América Latina, Avanços e Desafios [Microbial pest control in Latin America]. Piracicaba: FEALQ; 2008:137-170. Portuguese.
5. Pérez C, Fernandez LE, Sun J, Folch JL, Gill SS, Soberón M, Bravo A. Bacillus thuringiensis subsp. israelensis Cyt1 Aa synergizes Cry11Aa toxin by functioning as a membrane-bound receptor. Proc Nat Acad Sci US A. 2005;102(51):18303-18308.

6. Alves SB, Almeida JEM, Moino A, Alves LFA. Laboratory Techniques. In: Alves SB, editor. Insect Microbial Control. Piracicaba: FEALQ; 1998: 637-711.

7. Cavados CF, Fonseca RN, Chaves JQ, Rabinovitch L, Araújo-Coutinho CJ. Identification of entomopathogenic Bacillus isolated from Simulium (Diptera, Simuliidae) larvae and adults. Mem Inst Oswaldo Cruz. 2001; 96(7):1017-1021.

8. Oliveira EJ, Silva SEA, Rabinovitch L. A standardized protocol for the rapid detection of gelatin hydrolysis by Bacillus sphaericus. Isr J Entomol. 1998;32:141-146. Available from: http://www.entomology.org.il/ sites/default/files/pdfs/IJE-1998a.Oliveira.pdf. Accessed January 13, 2017.

9. da Silva KR, Rabinovitch R, Seldin L. Phenotypic and genetic diversity among Bacillus sphaericus strains isolated in Brazil, potentially useful as biological control agents against mosquito larvae. Res Microbiol. 1999;150(2):153-160.

10. Laemmli UK, Favre M. Maturation of the head of bacteriophage T4. I. DNA packaging events. J Mol Biol. 1973;80(4):575-599.

11. Nunes EL, dos Santos KR, Mondino PJ, Bastos Mdo C, GiambiagideMarval M. Detection of ileS-2 gene encoding mupirocin resistance in methicillin-resistant Staphylococcus aureus by multiplex PCR. Diagn Microbiol Infect Dis. 1999;34(2):77-81.

12. Reyes-Ramirez A, Ibarra JE. Fingerprinting of Bacillus thuringiensis type strains and isolates by using Bacillus cereus group-specific repetitive extragenic palindromic sequence-based PCR analysis. Appl Environ Microbiol. 2005;71(3):1346-1355.

13. Rohlf FJ. NTSYS-PC: Numerical Taxonomy and multivariate analysis system. New York: Applied Biostatistics, Inc; 1992. Available from: http://www.exetersoftware.com/downloads/ntsysguide21.pdf. Accessed January 13, 2017.

14. Sneath PHA, Sokal RR. Numerical Taxonomy: The principles and practice of numerical classification. San Francisco: Freeman; 1973.

15. Miteva V, Selenska-Pobell S, Mitev V. Random and repetitive primer amplified polymorphic DNA analysis of Bacillus sphaericus. J Appl Microbiol. 1999;86:928-936.

16. Woodburn MA, Yousten AA, Hilu KH. Random amplified polymorphic DNA fingerprinting of mosquito-pathogenic and nonpathogenic strains of Bacillus sphaericus. Int J Syst Bacteriol. 1995;45(2):212-217.

17. Nakamura LK. Phylogeny of Bacillus sphaericus-like organisms. Int $J$ Syst Evol Microbiol. 2000;50(Pt 5):1715-1722.
Research and Reports in Tropical Medicine

\section{Publish your work in this journal}

Research and Reports in Tropical Medicine is an international, peerreviewed, open access journal publishing original research, case reports, editorials, reviews and commentaries on all areas of tropical medicine, including: Diseases and medicine in tropical regions; Entomology; Epidemiology; Health economics issues; Infectious disease; Laboratory science and new technology in tropical medicine; Parasitology; Public health medicine/health care policy in tropical regions; and Microbiology. The manuscript management system is completely online and includes a very quick and fair peer-review system. Visit http://www.dovepress. com/testimonials.php to read real quotes from published authors. 